\title{
PERENCANAAN BETON MUTU TINGGI (KUAT TEKAN BESAR) DENGAN BAHAN TAMBAHAN
}

\author{
Almufid \\ Dosen Teknik Sipil \\ Fakultas Teknik \\ Universitas Muhammadiyah Tangerang \\ E-mil:almufid_st@yahoo.com
}

\begin{abstract}
ABSTRAK
Beton adalah element yang digunakan sebagai struktur dalam konstruksi teknik sipil yang dapat dimanfaatkan untuk banyak hal. Dalam teknik sipil struktur beton digunakan untuk bangunan pondasi, kolom, balok, plat/plat cangkang. Beton dikategorikan mempunyai mutu tinggi jika kuat tekannya $30 \mathrm{Mpa}$. Pada tahun 19601970, kriterianya naik menjadi $40 \mathrm{Mpa}$. Saat ini beton dikatakan sebagai beton mutu tinggi jika kuat tekannya diatas $50 \mathrm{Mpa}$ dan diatas $80 \mathrm{Mpa}$ adalah beton dengan mutu sangat tinggi (supartono, 1998) pada tahun 1980an beton mutu tinggi banyak digunakan untuk bangunan tingkat, terutama untuk element struktur kolom.

Didalam beton, agregat mempunyai peran penting yaitu $60 \%-80 \%$, dari volume beton, dari segi ekonomis harga agregat lebih rendah dibandingkan dengan PC, namun agregat terlalu banyak menyebabkan pasta cemen tidak mampu menyelimuti dan mengisi atau merekatkan seluruh permukiman butiran agregat.

Beberapa cara meningkatkan kinerja beton menjadi beton bermutu tinggi dan berkinerja tinggi adalah Mengurangi porositas beton dengan cara mengurangi air dalam adukan beton, Menambahkan aditif mineral seperti silicafume atau abu terbang, Menambahkan serat (beton berserat), Beton dengan pemadatan mandiri (self compacting concrete)
\end{abstract}

Kata Kunci: Beton, Kuat Tekan, Beton bermutu Tinggi

\section{PENDAHULUAN}

\subsection{Latar Belakang Masalah}

Banyak parameter yang mempengaruhi kekuatan tekan beton, Kekuatan tekan adalah kapasitas dari suatu bahan atau struktur dalam menahan beban yang akan mengurangi ukurannya. Kekuatan tekan dapat diukur dengan memasukkannya ke dalam kurva tegangan-regangan dari data yang didapatkan dari mesin uji. Diantaranya adalah kualitaas bahan-bahan penyusunnya, rasio air semen yang rendah dan kepadatan yang tinggi. Kekuatan tekan akhir sebuah beton keras akan ditentukan oleh Agregat yang terlemah. Agregat utama beton padat terdiri dari agregat kasar yang biasanya berbentuk batu dan matriks semen-pasir. Struktur beton bertulang bangunan atau gedung biasanya menggunakan mutu beton yang berbeda-beda, disesuaikan dengan perencanaan struktur masing-masing. Semakin berat beban (gaya normal, gaya lintang, momen) yang akan dipikul oleh suatu beton bertulang, maka sebaiknya menggunakan mutu beton yang semakin tinggi juga. Sehingga dibutuhkan beberapa faktor yang akan mempengaruhi agar kuat tekan beton bermutu tinggi, ada empat bagian utama yang mempengaruhi mutu dari kekuatan beton tersebut, yaitu: 
1. Penyerapan bahan yang memenuhi syarat.

2. Proses pencampuran agregat beton dengan pasta semen.

3. Proses pengecoran saat di lapangan. 4). Serta proses pengawetan beton yang

\subsection{Pengunaan Agregat}

Dalam pemakaian agregat pada pemakaiannya digunakan dengan komposisi tertentu agar mendapatkan suatu campuran beton yang ekonomis dan mempunyai nilai Kuat Tekan yang tinggi (Beton Mutu Tinggi).

\subsection{Cara Meningkatkan Beton Tinggi}

Beberapa cara meningkatkan kinerja beton menjadi beton bermutu tinggi dan berkinerja tinggi.

1. Mengurangi porositas beton dengan cara mengurangi air dalam adukan beton,

2. Menambahkan aditif mineral seperti silicafume atau abu terbang,

3. Menambahkan serat (beton berserat),

4. Beton dengan pemadatan mandiri (self compacting concrete).

\section{PEMBAHASAN BETON TINGGI}

\subsection{Material Beton Tinggi}

Pengunaan bahan yang memenuhi syarat adalah merupakan salah satu factor yang dapat mempengaruhi dalam pembuatan beton yang bermutu tinggi. Disini yang mempengruhi mutu suatu beton dapat dilihat dari beberapa factor berikut:

\section{a. Agregat Halus}

Agregat yang semua butirannya lolos ayakan $4.8 \mathrm{~mm}(\mathrm{SII}, 0052,1980)$ atau $4.75 \mathrm{~mm}$ (ASTM C33, 1982) atau $5.0 \mathrm{~mm}$ (BS, 812, 1976).

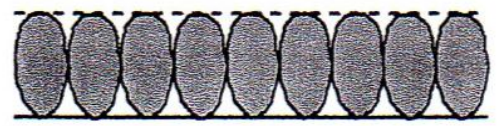

Gambar 1. Agregat Halus

\section{b. Agregat Kasar}

Agregat yang semua butirnya tertinggal diayakan $4.8 \mathrm{~mm}(\mathrm{SII}, 0052,1980)$ atau
$4.74 \mathrm{~mm}$ (ASTM C33,1982) atau 5,0 $\mathrm{mm}$ (BS,812,1976).

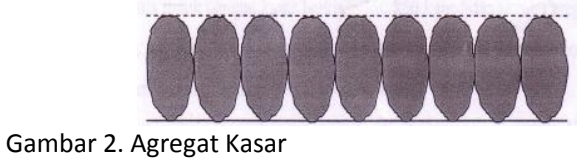

Pemerisaan Agregat kasar (Koral/split)

- Gradasi (sieve analysis)

- $\quad$ Spesific grafity dan penyerapan air

- $\quad$ Pengujian kekeran (los Angeles mechine)

- $\quad$ Berat isi agregat kasar (unit weight)

\section{c. Factor Semen (PC)}

Semen yang paling baik digunakan dalam pembuatan beton mutu tinggi adalah semen tipe II, yaitu semen Portland yang dalam penggunaannya mempunyai ketahanan terhadap sulfat dan kalor hidrasinya lebih kecil dari jenis satu. Semen ini biasanya digunakan untuk pekerjaan beton yang bervolume besar. Kandungan C3S kurang dari $50 \%$ dan kandungan C3A kurang dari 8\%. Jika kadar semen dinaikkan, maka kekuatan dan durabilitas beton juga akan meningkat. Semen (bersama dengan air) akan membentuk pasta yang akan mengikat agregat mulai dari yang paling besar (kasar) sampai yang paling halus.

\section{d. Faktor Air Semen (FAS)}

Dapat dicari berdasar jenis semen yang dipakai dan kuat tekan rata-rata silinder beton yang direncanakan pada umur 28 hari, ditetapkan nilai fas dengan gb. 7.8. Faktor air semen yang rendah, merupakan faktor yang paling menentukan dalam menghasilkan beton mutu tinggi, dengan tujuan untuk mengurangi seminimal mungkin porositas beton yang dihasilkan. Dengan demikian semakin besar volume faktor air-semen (fas) semakin rendah kuat tekan betonnya. Berikut ini beberapa persyaratan air menurut SKSNI, ACl, dan British Standard dan SNI 2012

Persyaratan air menurut $\mathrm{ACl} 318-83$, SNI 2012:

1. Bersih. 
2. Tidak mengandung minyak, alkali, garam, bahan organik yang berbahaya terhadap beton.

3. Untuk beton pratekan, atau beton yang dekat dengan alumunium, maka air tidak boleh mengandung $\mathrm{Cl}$.

4. Bukan air minum tidak boleh dipakai untuk campuran beton, kecuali uji adukan standar seperti tersebut dalam ASTM C109. kuat tekan umur 7 dan 28 hari tidak kurang dari $90 \%$ dibanding kuat tekan kubus yang dibuat dengan air minum.

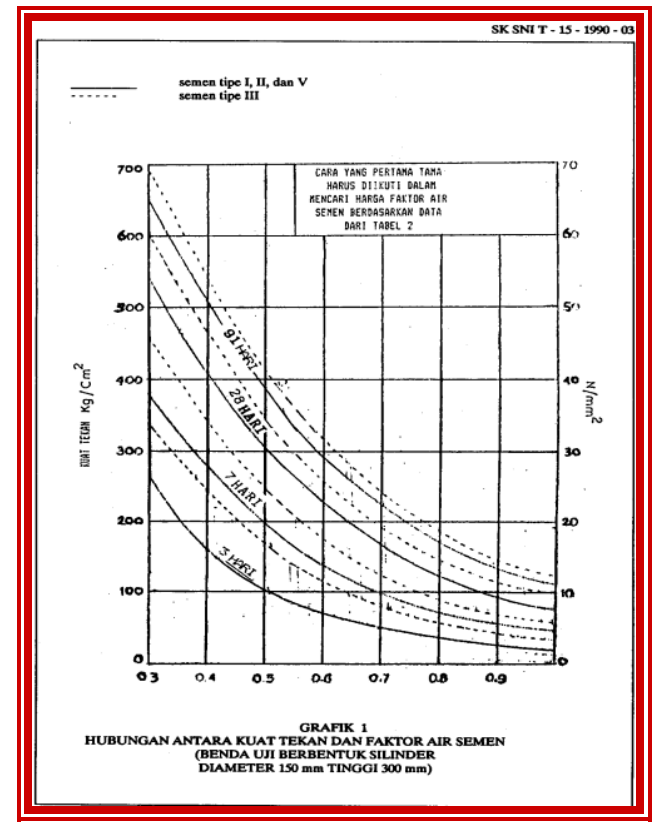

Gambar 3. Faktor Air Semen / Water of Contens

Terhadap Kuat Tekan Beton

\section{e. Mikrosilika (Silica fume)}

Mikrosilika (silicafume), yang merupakan produk sampingan dari suatu proses industri Silicon Metal, adalah merupakan bahan tambahan (aditif) yang sangat baik dan berdayaguna tinggi untuk campuran beton, dalam tujuan menghasilkan beton berkinerja tinggi.

Bila mikrosilika, yang bersifat pozzolan dengan ukuran butiran yang sangat halus, dan pada umumnya mengandung lebih dari $80 \% \mathrm{SiO}_{2}$ aktif, ditambahkan pada campuran beton, ternyata akan dapat bereaksi dengan
$\mathrm{Ca}(\mathrm{OH})_{2}$ yang dihasilkan dari proses hidrasi $\mathrm{C}_{3} \mathrm{~S}$ dan $\mathrm{C}_{2} \mathrm{~S}$, untuk menghasilkan gel $\mathrm{CSH}$ yang baru (gel CSH-2).

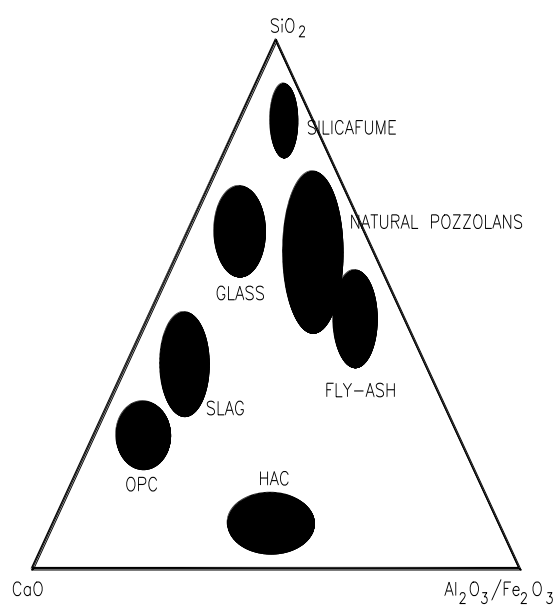

Gambar 4. Bentuk Silikafume

$2\left(3 \mathrm{CaO} . \mathrm{SiO}_{2}\right)+6 \mathrm{H}_{2} \mathrm{O} 3 \mathrm{CaO} .2 \mathrm{SiO}_{2} \cdot 3 \mathrm{H}_{2} \mathrm{O}$ (gel $\mathrm{CSH}-1)+3 \mathrm{Ca}(\mathrm{OH})_{2} \mathrm{Ca}(\mathrm{OH})_{2}+\mathrm{SiO}_{2}(\mathrm{SF})+\mathrm{H}_{2} \mathrm{O}$ gel CSH-2

Jika kadar $\mathrm{SiO}_{2}$ di dalam mikrosilika sangat tinggi sehingga masih terdapat kandungan $\mathrm{SiO}_{2}$ dalam mikrosilika yang tidak terpakai dan berlebih pada reaksi primer $\mathrm{SiO}_{2}$, maka kelebihan $\mathrm{SiO}_{2}$ masih bisa bereaksi dengan $\mathrm{CSH}-2$, untuk menghasilkan gel CSH-3 yang lebih padat sehingga pasta semen akan semakin kuat, dan yang akan meningkatkan juga daya lekat pasta semen dengan agregat.

\subsection{Manfaat Penambahan Silikafume pa- da kinerja Beton}

Secara umum, berdasarkan hasil-hasil penelitian yang dilakukan, penggunaan mikrosilika sebagai aditif mineral akan dapat memperbaiki banyak aspek dalam kinerja beton, antara lain:

1. meningkatkan mutu beton,

2. meningkatkan kemudahan pemompaan beton walaupun kemungkinan nilai slump yang didapat lebih kecil,

3. meningkatkan kekedapan beton terhadap penetrasi air meningkatkan ketahanan beton terhadap sulfat dan klorida 
4. mengurangi susut dan rangkak beton

5. meningkatkan keawetan (durability) beton.

\section{METODE PENELITIAN}

Untuk menghasilkan beton bermutu tinggi maka dibutuhkan prosedur yang benar dan cermat pada keseluruhan proses produksi beton yang meliputi:

\subsection{Pengujian agregat}

1. Agregat halus untuk beton dapat berupa pasir alam sebagai hasil desintergris alami dari batu-batuan atau berupa pasir buatan yang dihasilkan oleh alat pemecahan batu.

2. Agregat halus harus terdiri dari butirbutir yang tajam dan keras. Bersifat kekal artinya tidak pecah/hancur oleh pengaruh cuaca-terik matahari dari hujan.

3. Tidak boleh mengandung Lumpur dari 5\% (ditentukan terhadap berat kering) lumpur adalah bagian-bagian yang dapat melalui ayakan $\varnothing 0.063 \mathrm{~mm}$. Apabila kadar lumpur melampaui 5\% maka agregat halus dicuci.

4. Tidak boleh mengandung bahan- bahan organis terlalu banyak yang dapat dibuktikan dengan percobaan AbramsHarder. dengan larutan 3\% NaOH-130 $\mathrm{cc}+$ pasir $200 \mathrm{cc}$, dikocok dan didiamkan 24 jam. Jika warna cairan bening muda berati tidak ada bahan organis baik. Warna Kuning Tua pasir mengandung kotoran organis tidak baik, apabila dipakai harus dicuci berwarna merah kuning-coklat tua jelek, maka pasir tdk bisa dipakai.

5. Agregat halus terdiri dari butir-butir yang beraneka ragam besarnya. Dapat diselidiki dengan analisa saringan (sieve analasyis) dengan susunan ayakan sbb;

1) sisa di atas ayakan $\varnothing 4 \mathrm{~mm}$, harus minimum $2 \%$ berat sisa di atas ayakan $\varnothing 1 \mathrm{~mm}$, harus minimum $10 \%$ berat sisa di atas ayakan $\varnothing 0.25 \mathrm{~mm}$, harus minimum $80 \%$ berat dan $95 \%$ berat.

2) Apabila tidak tersedia susunan ayakan seperti diatas, susunan ayakan lain dapat dipakai asal mempunyai ukuran lubang yang mendekati ukuran diatas.

3) Pasir laut tidak dapat dipakai sebagai agregat halus untuk semua mutu beton, kecuali dengan petunjuk-petunjuk dari lembaga pemeriksaan bahan. (garam/ $\mathrm{NaCl}$ ).

\section{2 Semen (PC)}

Semen Portland (PC) umum pada berbagai tipe (yang memenuhi spesifikasi standar ASTM C 150) dapat digunakan untuk memperoleh campuran beton dengan kekuatan tekan sampai dengan $50 \mathrm{Mpa}$. Untuk mendapatkan kuat tekan yang lebih tinggi saat mempertahankan workability yang baik, sangat perlu untuk menggunakan admixture yang dikombinasikan dengan semen. Pada kasus tersebut, kompabilitas semen-admixture menjadi sebuah hal yang penting.

Feret formula:

$$
R=K\left[\frac{1}{1+3 w / c}\right]^{2}
$$

Abrams formula:

$$
R=\frac{A}{B^{w / c}}
$$

$$
\log R=\log A-(w / c) \log B
$$

$\log R=\log A-(1,5 w / c) \log B$

$\log \mathrm{R}=\log \mathrm{A}-(w / c) \log B w$

Bolomev formula:

$$
R=K_{B}\left[\frac{1}{w / c}-0.50\right]
$$



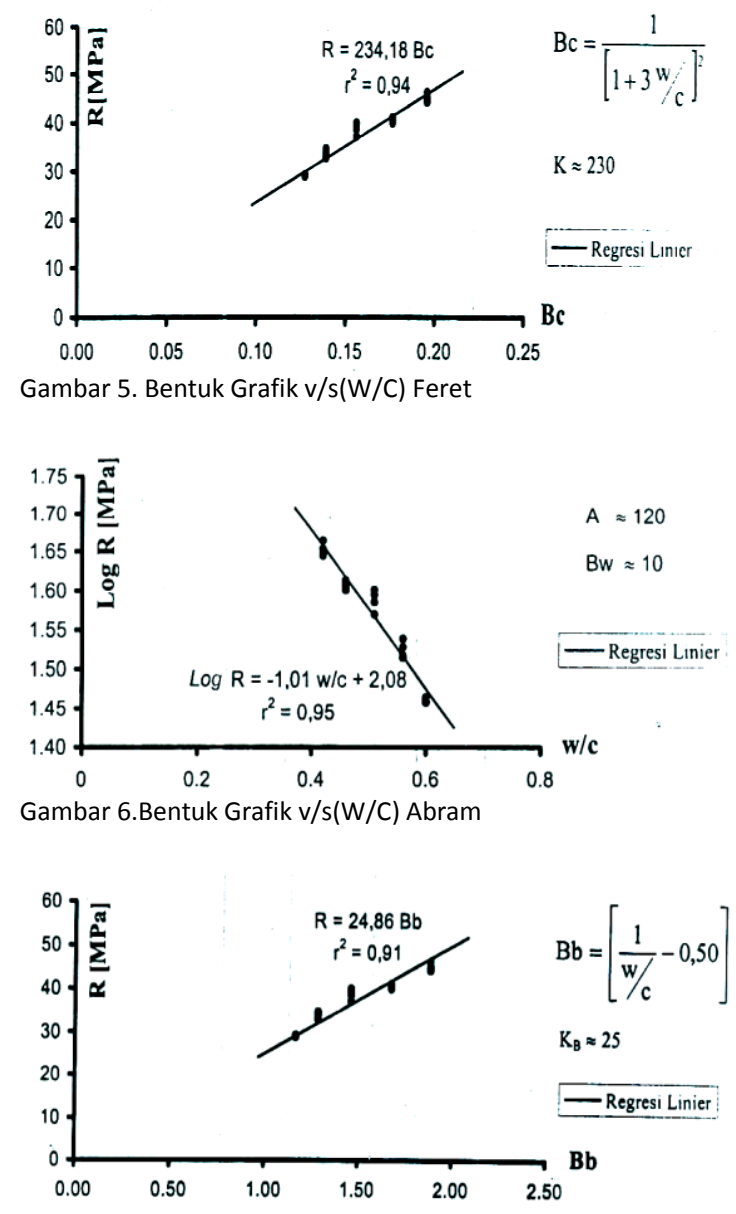

Gambar7.Bentuk Grafik v/s(W/C) Bolomay

Pengalaman telah memperlihatkan bahwa, dengan penggunaan tipe superplasticizer naphthalene sulfonate atau melamine sulfonate, semen portland dengan kadar $\mathrm{C}_{3} \mathrm{~A}$ dan alkali yang rendah umumnya menghasilkan campuran beton yang memperlihatkan hilangnya slump tinggi sejalan dengan waktu. Situasi ini telah berubah karena telah dilaporkan bahwa polyacrylate copolymer, sebuah generasi baru superplasticizer, tidak menyebabkan kehilangan slum yang berlebihan pada kebanyakan jenis semen Portland maupun semen portland campuran.

\subsection{Silicafume}

Dalam teknologi beton, Silica Fume

(SF) digunakan sebagai pengganti sebagian dari semen atau bahan tambahan pada saat sifat-sifat khusus beton dibutuhkan, seperti penempatan mudah, kekuatan tinggi, permeabilitas rendah, durabilitas tinggi, dan lain sebagainya. Silica fume merupakan hasil sampingan dari produk logam silikon atau alloy ferosilikon. Menurut standar "Spesification for Silica Fume faor Use in Hydraulic Cement Concrete and Mortal" (ASTM. C.1240, 1995: 637-642), silica fume adalah material pozzolan yang halus, dimana komposisi silika lebih banyak dihasilkan dari tanur tinggi atau sisa produksi silikon atau alloy besi silikon (dikenal sebagai gabungan antara micro silica dengan silica fume), Penggunaan silica fume dalam campuran beton dimaksudkan untuk menghasilkan beton dengan kekuatan tekan yang tinggi. Beton dengan kekuatan tinggi digunakan, misalnya, untuk kolom struktur atau dinding geser, pre-cast atau beton pra-tegang dan beberapa keperluan lain. Kriteria kekuatan beton berkinerja tinggi saat ini sekitar 50-70 Mpa untuk umur 28 hari. Penggunaan silica fume berkisar 0$30 \%$ untuk memperbaiki karakteristik kekuatan keawetan beton dengan faktor air semen sebesar 0,34 dan 0,28 dengan atau tanpa superplastisizer dannilai slump $50 \mathrm{~mm}$ (Yogerdran, et al, 1987: 124-129).

Keuntungan-keuntungan penggunaan silica fume dan superplatisticizer pada campuran beton menurut beberapa hasil penelitian terdahulu antara lain seperti kekuatan tekan hancurnya lebih tinggi, kekuatan tarik lebih tinggi, rangkaknya lebih kecil, regangan yang terjadi kecil, susutnya kecil, modulus elastisitasnya tinggi, ketahanan terhadap serangan klorida tinggi, ketahanan terhadap keausan tinggi dan permeabilitas lebih kecil (220). Dalam hal ketahanan terhadap serangan klorida tinggi, menurut Sorensen (Rachee dan Kumar, 1989), mengatakan bahwa dengan berkurangnya permeabilitas beton, berarti juga akan berkurangnya penetrasi serangan kimia. 
Kendala-kendala yang ada dalam penggunaan silica fume antara lain seperti, handling/pelaksanaan, bahaya kesehatan kerja, air entrainment, plastic shringkage, dan quality control. SF merupakan bahan sangat lembut dan mudah sekali terbang kena angin, maka perlu diperhatikan dalam pelaksanaan loading, penangkutan, peyimpanan dan pencampuran. Sehubungan dengan kesehatan kerja, karena SF sangat halus, kemungkinan penghisap SF oleh pekerja akan terjadi, oleh karena itu pekerja harus dilengkapi dengan lat pelindung pernafasan.

\subsection{Pengadukan}

Secara umum, pengadukan dengan mesin harus dilakukan menggunakan mesinmesin yang telah di setujui penggunaannya (PB,1989:27) Mesin pengaduk harus di putar sesuai dengan kecepatan yang rekomendasikan oleh pabrick pembuatnya.

Setelah pencampuran seluruh badan dalam batchin, harus dilakukan pengadukan kembali minimal selam 1.5 menit, kecuali bila dapat di buktikan bahwa pengadukan yang lebih pendek mampu memberikan hasil yang lebih memuaskan dan memenuhi pengujian keseragaman pengadukan yang ditetapkan dalam ASTM C.94. Ketentuan mengenai waktu pengadukan dapat di lihat pada. Waktu pengadukan Minimal kapasitas dari mixer (m3) ASTM C.94 dan ACl 318

$\begin{array}{ll}0.8-3.1 & 1 \text { Menit } \\ 3.8-4.6 & 2 \text { Menit } \\ 7.6 & 3 \text { Menit }\end{array}$

\subsection{Pengangkutan}

Beton diangkut dengan berbagai cara, mulai dari truk readi mix, sampai pompa beton. Sedikitnya ada 3 macam gerakan, yaitu dari pengadukan sampai ke lokasi, dari lokasi kebagian yang dicor secara vertikal maupun horizontal.

Hal-hal yang harus di perhatikan dalam pengangkutan beton dari tempat penyiapan adukan ke tempat pengecoran adalah sbb:
1. Harus dihindari adanya kekurangan bahan yang akan dicor pada proses pengadukan.

2. Pengangkutan adukan beton harus lancar sehingga tidak terjadi perbedaan waktu pengikatan beton yang akan dicor.

3. Adukan beton umumnya sudah harus dicor dalam waktu 1 jam setelah pengadukan dengan air dimulai dan $\max 2$ jam setelah pengadukan

4. Jika jangka waktu pengangkutan yang panjang maka digunakan bahan penghambatan pengitan betom

\section{KESIMPULAN}

Beberapa cara meningkatkan kinerja beton menjadi beton bermutu tinggi dan berkinerja tinggi

1. Mengurangi porositas beton dengan cara mengurangi air dalam adukan beton,

2. Menambahkan aditif mineral seperti silicafume atau abu terbang,

3. Menambahkan serat (beton berserat),

4. Beton dengan pemadatan mandiri (self compacting concrete),

5. Perawatan dengan isolasi permukaan beton.

\section{DAFTAR PUSTAKA}

Anonim, CIP 33 - High Strength Concrete, National Ready Mixed Concrete Association. 2010

Civil Engineering Portal, http://www.engineeringcivil.com/, portal khusus untuk teknik sipil.

Kartini, Wahyu. 2002. "Pengaruh Copper Slag sebagai Cementitius terhadap Kuat Tekan pada beton."

Kosmatka, Steven H., Kerkhoff, Beatrix, dan Panarese, William C., 2003. Design and 
Con-trol of Concrete Mixture. Portland Cement Association, Illionis.

Mehtar, P. Kumar, dan Monteiro, Paulo J.M., 2006. Concrete - Microstructure, Properties and Materials, 3rd edition., McGraw-Hill, New York.

Supartono, FX - Beton Mutu Tinggi, UI - Press 2010 